\title{
LOTUS SEEDPOD-BASED CARBON QUANTUM DOTS: PREPARATION, CHARACTERIZATION AND APPLICATION FOR Fe(III) DETECTION
}

\author{
KVANTNE PIKE OGLJIKA V OBLIKI STROKA LOTUSOVIH \\ SEMEN: PRIPRAVA, KARAKTERIZACIJA IN UPORABA ZA \\ DETEKCIJO Fe(III)
}

\author{
Zhouling Xie ${ }^{1}$, Jianfa Sun ${ }^{2}$, Zeijun Zhou ${ }^{3}$, Shibin $\mathrm{Xia}^{1}{ }^{\text {* }}$ \\ ${ }^{1}$ School of Resources and Environmental Engineering, Wuhan University of Technology, no. 171 Luoshi Street, \\ Hongshan District, Wuhan 430070, China \\ ${ }^{2}$ Key Laboratory of Arable Land Conservation (Middle and Lower Reaches of Yangtze River), Ministry of Agriculture/College of \\ Resources and Environmental Sciences, Huazhong Agricultural University, Wuhan 430070, China \\ ${ }^{3}$ China Petroleum \& Chemical Corporation Jianghan Oilfield Branch No. 1 Gas Production Plant, Chongqing 400000, China
}

Prejem rokopisa - received: 2020-08-13; sprejem za objavo - accepted for publication: 2020-10-05

doi:10.17222/mit.2020.160

\begin{abstract}
Lotus seedpod (LS) was employed as a carbon source for the synthesis of carbon quantum dots (CQDs) using an economical and facile hydrothermal synthesis method. LS-CQDs were characterized with different techniques, including TEM, FTIR, PL, XRD, XPS, Raman spectroscopy and Uv-vis. The average particle size of LS-CQDs was found to be $2.1 \pm 0.17 \mathrm{~nm}$. The properties of the excitation-dependent photoluminescence of LS-CQDs were determined, and the quantum yield was calculated to be $1.9 \%$. The quenching effect of LS-CQDs on Fe(III) ions was also investigated. The normalized linear relationship between the increasing Fe(III) ion concentration and the fluorescence-emission intensities of LS-CQDs was established. Furthermore, the quenching mechanism for the reaction between Fe(III) ions and LS-CQDs was elucidated.

Keywords: lotus seedpod, carbon quantum dots, Fe(III) determination
\end{abstract}

Avtorji so uporabili strok lotusovih semen (LS) kot izvor za sintezo kvantnih pik ogljika (CQD) z uporabo ekonomične in enostavne metode hidrotermalne sinteze. LS-CQDs so okarakterizirali z različnimi tehnikami, vključno s TEM, FTIR, PL, XRD, XPS, Ramanovo spektralno UV-vis analizo. Izmerjena povprečna velikost delcev LS-CQDs je bila 2,1 $\pm 0,17 \mathrm{~nm}$. Določili so lastnosti povzročeno odvisne fotoluminescence LS-CQDs in izračunani kvantni doprinos je bil $1.9 \%$. Raziskali so tudi kalilni efekt LS-CQDs na Fe(III). Določili so normalizirano linearno zvezo med naraščanjem koncentracije $\mathrm{Fe}(\mathrm{III})$ in intenziteto emisije fluorescence LS-CQDs. Nadalje so avtorji pojasnili še kalilni mehanizem reakcije med Fe(III) ioni in LS-CQDs.

Ključne besede: strok lotusovih semen, kvantne pike ogljika, določevanje Fe(III)

\section{INTRODUCTION}

Iron, especially $\mathrm{Fe}(\mathrm{III})$ ions, is one of the most basic, richest and essential metal elements in an organism, which participates in the formation of various enzymes and proteins as well as regulating many chemical reactions in living organisms. ${ }^{1,2}$ Insufficient or excessive $\mathrm{Fe}(\mathrm{III})$ in the human body can disrupt the metabolic activity and affect physical health, leading to the development of chronic diseases such as anemia, liver and kidney damage and heart failure. ${ }^{3,4}$ Besides, an $\mathrm{Fe}(\mathrm{III})$ ion contamination has become an increasingly severe environmental problem, attracting much attention in recent year. ${ }^{5}$ Therefore, the research on the Fe(III) detection is of great importance to both the environment and human health.

At present, the methods used for detecting Fe(III) include spectrophotometry, atomic spectroscopy, the electrochemical method and mass spectrometry. ${ }^{6-11}$ These an-

*Corresponding author's e-mail:

xiashibin@126.com (Shibin Xia) alytical methods usually have a broad detection range, high sensitivity and excellent repeatability. However, there are also shortcomings such as a long detection time, cumbersome sample-preparation process, complicated operation, possible interference with another ion and expensive equipment. Thus, it is necessary to design a simple, fast and accurate method for the Fe(III) detection. In comparison with the other methods, the fluorescent-probe method is highly sensitive, relatively simple and more rapid, exhibiting fewer background signals and spanning over a wider linear dynamic range. It has become an important analytical method for the determination of metal ions..$^{12-17}$ As a fluorescent probe, carbon quantum dot (CQD) has received considerable attention due to its advantages including a facile synthesis, and cost efficiency and adjustable fluorescence emission. ${ }^{18}$

A lotus seedpod (LS) is the receptacle surface of a lotus with many honeycomb holes. LS is usually treated as a waste and low-calorific fuel, but it is also used as food or a medicinal substance. ${ }^{19}$ Previous studies showed that LSs can be used as adsorbents or functional materials 
due to their high specific surface area after pyrolysis activation. ${ }^{20,21}$ Hence, there is a great potential for LSs to be applied in the development of novel CQDs. Compared with the other carbon sources, lotus seedpod exhibits obvious advantages including a low cost and an easy access.

In this study, LS was employed as s carbon source for synthesizing CQDs (hereinafter referred to as LS-CQDs) via the hydrothermal-synthesis method. The synthesized LS-CQDs were characterized with transmission electron microscopy (TEM), Raman spectroscopy, X-ray diffraction (XRD), X-ray photoelectron spectroscopy (XPS) and Fourier transform infrared (FTIR). The effect of the quenching mechanism of $\mathrm{Fe}(\mathrm{III})$ on the photoluminescence (PL) intensity of LS-CQDs was also elucidated.

\section{EXPERIMENTAL PART}

\subsection{Instruments and materials}

A homegrown mature lotus seedpod was purchased at a local supermarket (Wuhan, Hubei, in the summer). The reagents used in this study included quinoline sulfate, calcium chloride, ferric chloride, chromium tri-chloride, sodium chloride, aluminum chloride, potassium chloride, magnesium chloride and zinc chloride. All the reagents were of analytical grade and were used as received. Distilled water was used to prepare the $\mathrm{Fe}$ (III) ion solution.

TEM measurement was carried out using a high-resolution JEM-2100F transmission electron microscope. Raman spectral measurement was conducted using an InVia Raman spectrometer. The PL intensity was measured with spectrofluorometric detection (SigmaAldrich). The particle-size distribution of CQDs was analyzed using dynamic laser-light scattering. Spectrophotometric measurement was performed using an UNICOWFUV-2 UV-Vis spectrometer. XRD patterns were assessed with a D8 Advance X-ray diffractometer. XPS measurement was conducted using an ESCALAB $\mathrm{Xi}+\mathrm{X}$-ray photoelectron spectrum analyzer. FTIR assessment was carried out using a Nexus FTIR spectrometer. Other instruments such as an electronic balance (BS223S), drying box (DGG-9123A), PTFE-lined hydrothermal synthesis reactor (LSRP-25), centrifuge (TG16-II) and lyophilizer (JL-D10N-50C) were also used in this study.

\subsection{Preparation of a dried $L S$}

Lotus seeds were removed from a fresh LS and the remaining LS was dried at a ventilated place for 30 days to prepare a dried LS. Then, the obtained dried LS was ground into powder and filtered through a 200-mesh sieve.

\subsection{Preparation of LS-CQDS}

Two grams of dried LS powder and $50 \mathrm{~mL}$ of pure water were mixed and placed into the PTFE-lined hydrothermal synthesis reactor, followed by heating for $3 \mathrm{~h}$ at $180{ }^{\circ} \mathrm{C}$. After the reaction, the obtained solution was filtered through a $0.45-\mu \mathrm{m}$ polyether sulfone membrane. The filtrate was then centrifuged at $10,000 \mathrm{~min}^{-1}$ for $15 \mathrm{~min}$ and the supernatant was filtered again using a $0.22-\mu \mathrm{m}$ syringe filter. The resulting filtrate was dialyzed for 2 days and the dialysis fluid was changed daily. After completing the dialysis, the solution was freeze-dried to obtain the desired solid LS-CQDs.

\subsection{Determination of the fluorescence quantum yield $(Q Y)$ and lifetime}

The QY of LS-CQDs was measured with a standard procedure. Quinoline sulfate (QS) with $55 \%$ QY was employed as the reference standard. The integrated fluorescent intensity and absorbance (A) values of LS-CQDs and QS solution were determined at the same excitation wavelength and the percentage of QY were calculated in accordance with Equation (1):

$$
Q Y_{\mathrm{CQD}}=Q Y_{\mathrm{QS}} \cdot \frac{I_{\mathrm{CQD}}}{I_{\mathrm{QS}}} \cdot \frac{A_{\mathrm{QS}}}{A_{\mathrm{CQD}}} \cdot\left(\frac{n_{\mathrm{CQD}}}{n_{\mathrm{QS}}}\right)^{2} \cdot 100 \%
$$

where $Q Y$ represents the fluorescence quantum yield $(\%), I$ refers to the integrated fluorescent intensity, A indicates the absorbance value and $\mathrm{n}$ stands for the refractive index of the solvent.

To determine the fluorescence lifetime of LS-CQDs, Equation (2) was used for the exponential-decay-curve fitting: 22

$$
I_{\mathrm{t}}=\sum_{1}^{n} A_{n} \cdot e^{\frac{-t}{\tau_{n}}}
$$

where I represents the fluorescence intensity, A stands for the weight coefficient and $\tau$ represents the fluorescence lifetime.

\section{Determination of $\mathrm{Fe}(I I I)$ ions with $L S-C Q D$ s}

Solid LS-CQDs were dissolved and diluted to a $1 \mathrm{mg} / \mathrm{L}$ solution with ultrapure water. For the determination of $\mathrm{Fe}(\mathrm{III})$ ions, $2 \mathrm{~mL}$ of different concentrations of the Fe (III) ion solution were mixed with a CQD solution (ratio $=1: 1, v / v)$. After a thorough mixing, the fluorescence intensity of the LS-CQDs solution was determined.

\section{RESULTS}

\subsection{Morphological characterization}

As illustrated in Figure 1a, the morphology of LS-CQDs exhibited a spherical shape with a uniform dispersion, which confirmed a successful preparation of LS-CQDs. ${ }^{23}$ Figure $\mathbf{1 b}$ demonstrates the crystal lattices 

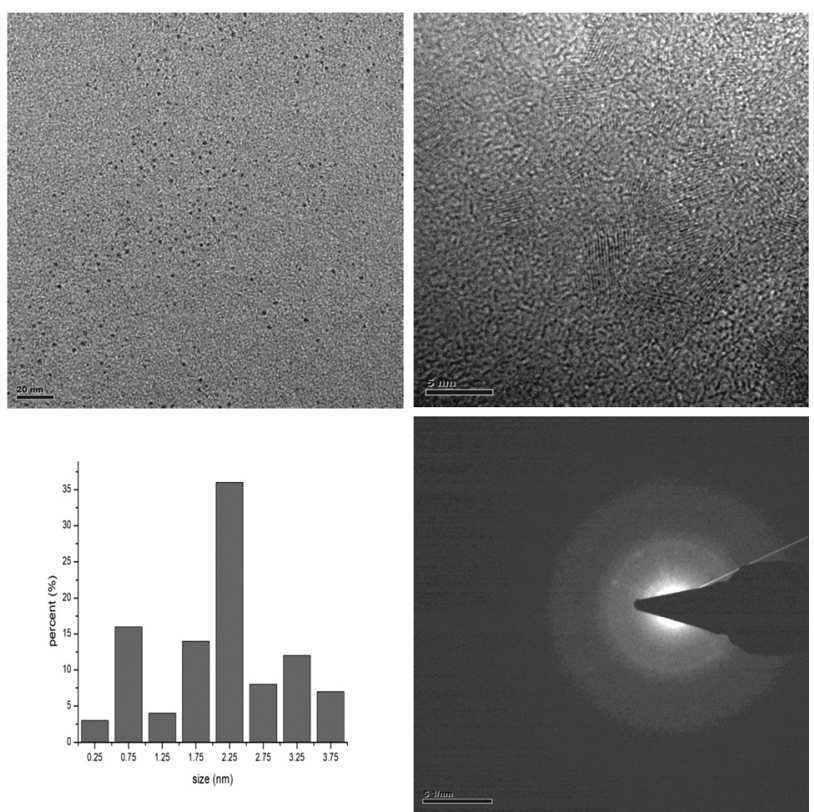

Figure 1: a) TEM image, b) high-resolution TEM image, c) particle-size distribution, d) SAED pattern of LS-CQDs

of LS-CQDs (lattice spacing $=0.22 \mathrm{~nm}$ ), which are slightly smaller than those of the CQDs reported in other studies. ${ }^{24,25}$ Figure 1c indicates that the average particle size of LS-CQDs is $2.1 \mathrm{~nm}$ (ranging from $0.5 \mathrm{~nm}$ to $4 \mathrm{~nm}$ ). Figure 1d reveals the selected-area electron-dif-
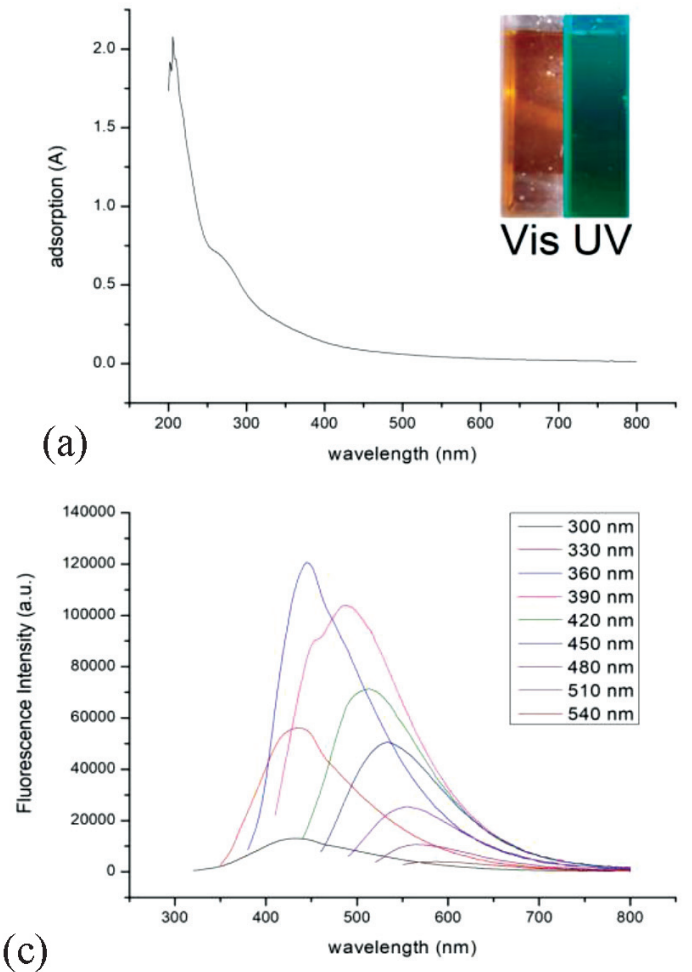

fraction (SAED) pattern of LS-CQDs, indicating the amorphous phase of LS-CQDs. ${ }^{26}$

\section{Photoluminescence and spectroscopic characterization}

Figure 2a indicates the UV-visible spectrum of LS-CQDs. The existence of the maximum absorption peak at around $204 \mathrm{~nm}$ is due to the $\pi-\pi^{*}$ transition of the aromatic $\mathrm{C}=\mathrm{O}$ bond. ${ }^{27}$ In the inset, the LS-CQD solution is brown under the visible-light illumination, while emitting bright green under the UV-light illumination.

Figure $\mathbf{2 b}$ indicates the fluorescence emission and excitation of LS-CQDs. The maximum adsorption peak of the fluorescence intensity was located at $360 \mathrm{~nm}$ in the excitation spectra. Figure 2c indicates the excitation-dependent property of LS-CQDs, suggesting the occurrence of a redshift with the increasing excitation wavelengths. The PL is generated from a pre-existing surface defect on LS-CQDs, playing a major role in trapping the excitation energy and emitting light at a particular excitation wavelength, thus leading to an excitation-dependent property.

As shown in Figure 2d, different fluorescence-lifetime values were observed and an average fluorescence-decay lifetime of $5.50 \mathrm{~ns}$ was determined. The quantum yield of LS-CQDs was calculated to be $1.9 \%$, which is relatively low compared to the CQDs synthesized from other carbon sources. ${ }^{28,29}$
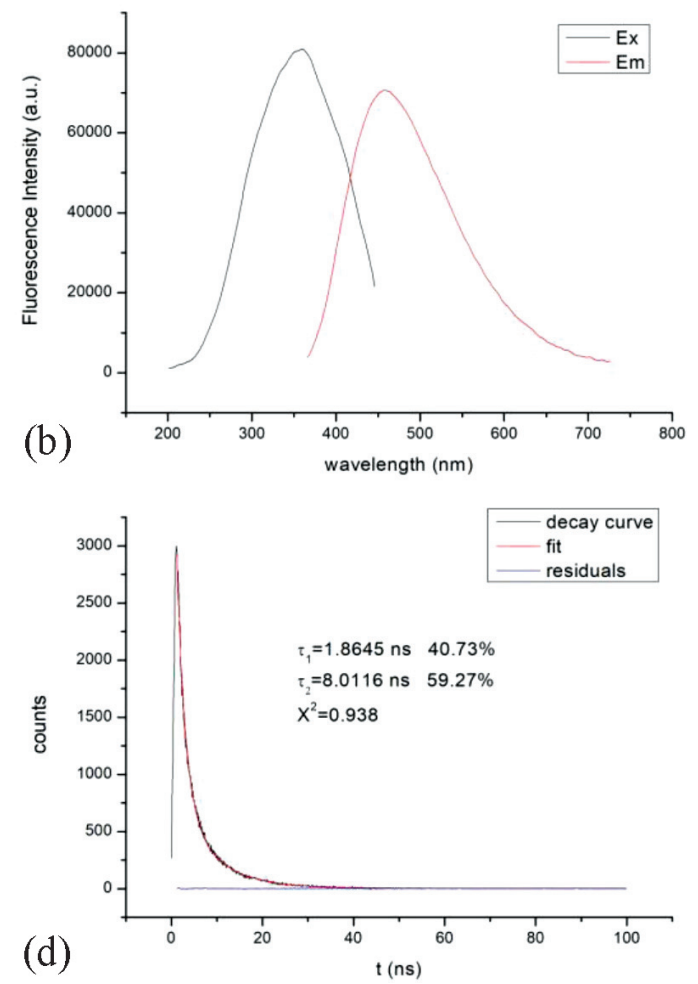

Figure 2: a) UV-visible spectrum (inset: photographs of LS-CQD solution under visible light (left) and UV light (right)), b) fluorescence emission and excitation spectra of LS-CQDs, c) emission spectra of LS-CQDs at excitation wavelengths varying from $300 \mathrm{~nm}$ to $540 \mathrm{~nm}$, d) fluorescence-decay lifetime of LS-CQDs at a 360-nm excitation wavelength 


\subsection{Surface function group and structure characteriza- tion}

The functional groups on the surfaces of LS-CQDs were characterized with an FTIR analysis. As shown in Figure 3a, a broad peak was observed at $3388 \mathrm{~cm}^{-1}$, which corresponded to the $-\mathrm{OH}$ stretching vibration peak. ${ }^{30}$ The peak at $2931 \mathrm{~cm}^{-1}$ was ascribed to the symmetric $-\mathrm{C}-\mathrm{H}$ stretching vibration group, while the peaks at $1633 \mathrm{~cm}^{-1}$ and $1410 \mathrm{~cm}^{-1}$ were attributed to the presence of a $-\mathrm{COO}$ group. The peaks at $1256 \mathrm{~cm}^{-1}$ and 1048 $\mathrm{cm}^{-1}$ were corresponded to $\mathrm{C}-\mathrm{O}-\mathrm{C}$ and $-\mathrm{C}-\mathrm{N}$ stretching vibration groups, respectively. The peak at $611 \mathrm{~cm}^{-1}$ was ascribed to the $\mathrm{C}-\mathrm{C}$ stretching vibration group.

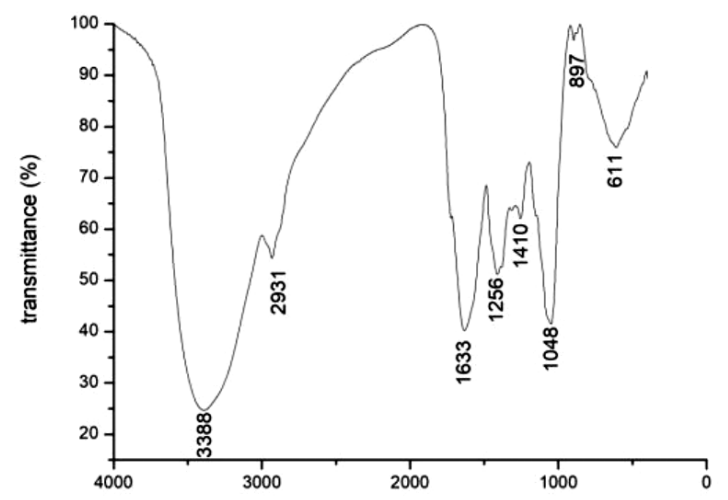

(a)
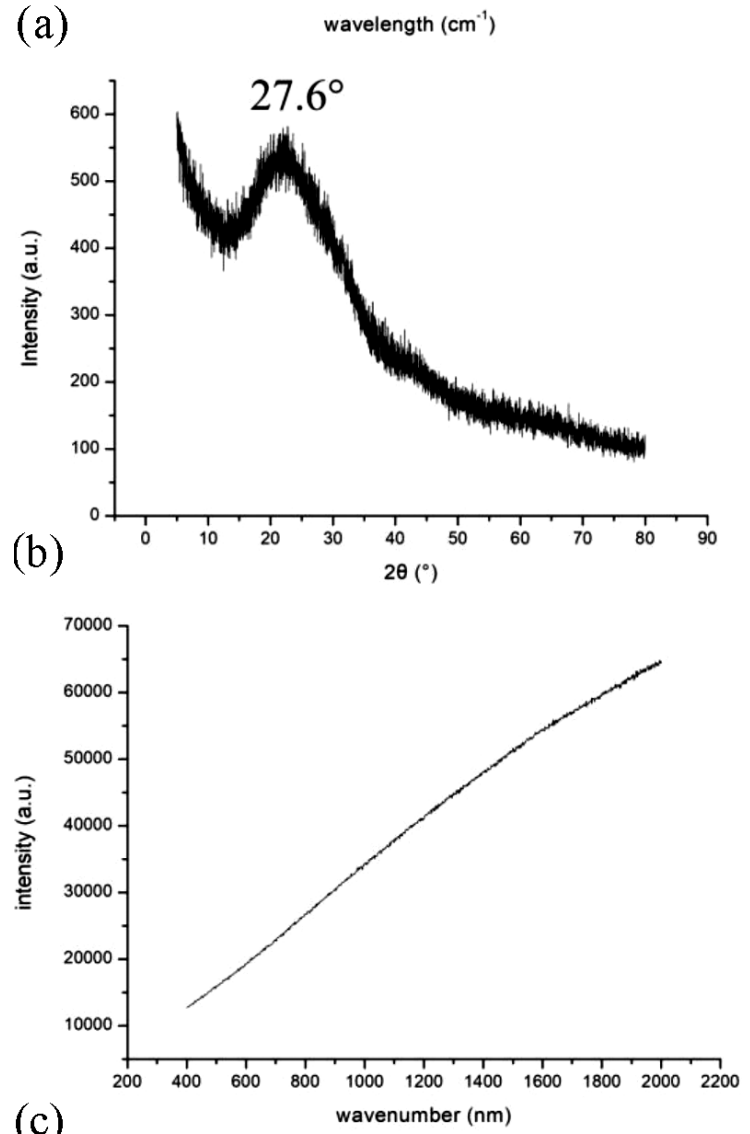

(c)

Figure 3: a) FTIR, b) XRD and c) Raman spectra of LS-CQDs
Figure 3b indicates the XRD pattern of LS-CQDs. There is an obvious absorption peak at around $27.6^{\circ}$, which demonstrates the amorphous form of LS-CQDs. This result is similar to a previous study. ${ }^{31}$

Figure 3c indicates the Raman spectrum of LS-CQDs. Typically, the fluorescence intensities of the $\mathrm{D}$ and $\mathrm{G}$ peaks in the Raman spectrum were used to calculate the graphitization degrees of LS-CQDs. As shown in Figure 3c, both the G peak (representing crystallinity) and $\mathrm{D}$ peak (representing the degree of disorder) are statistically insignificant. It is deduced that the fluorescence interference from LS-CQDs may impede the Raman-spectrum signal..$^{32,33}$
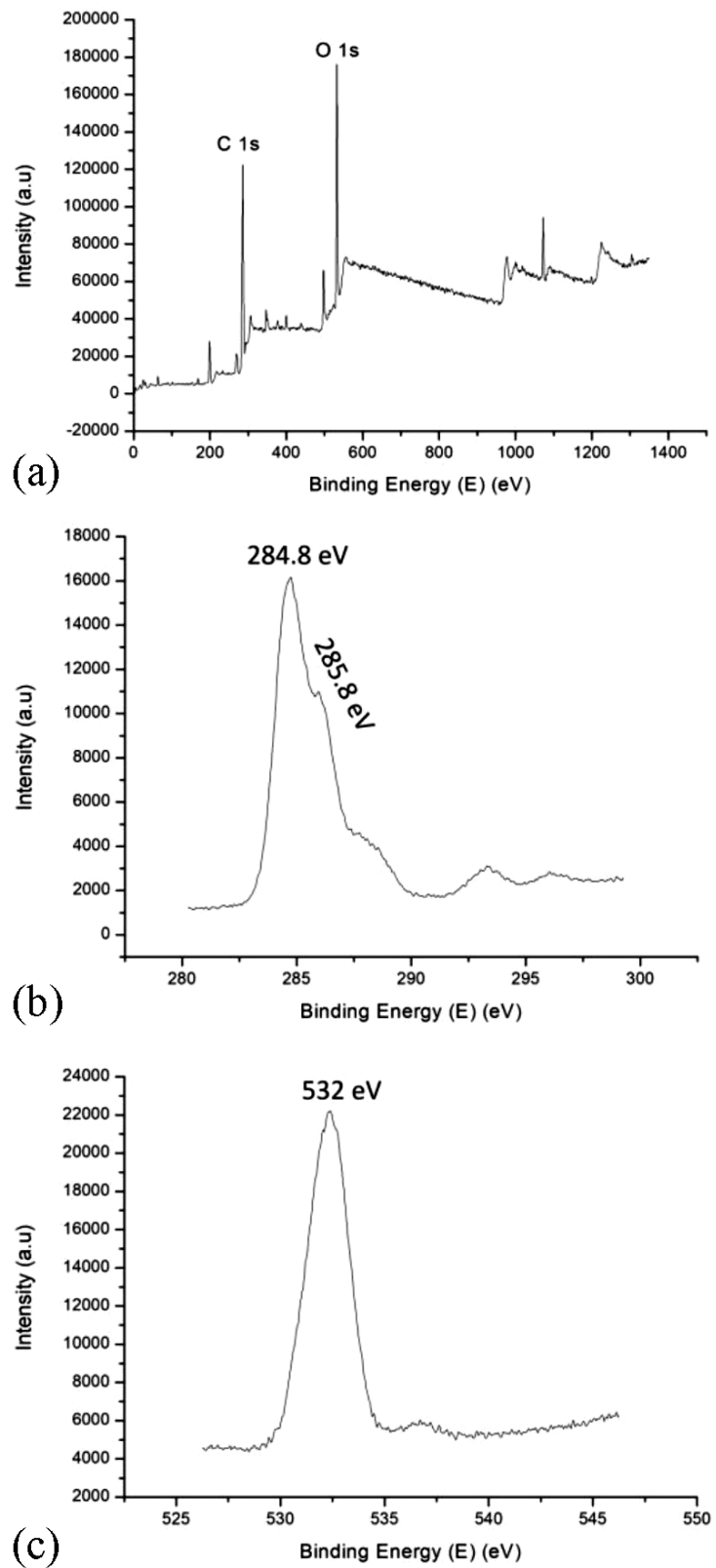

Figure 4: XPS spectra of LS-CQDs: a) XPS survey spectrum and binding-energy spectra of b) $\mathrm{C} 1 \mathrm{~s}$ and c) $\mathrm{O} 1 \mathrm{~s}$ 


\subsection{XPS analysis}

X-ray photoelectron spectroscopy was employed to assess the surface composition and oxidation state of LS-CQDs. Figure 4a shows an XPS survey spectrum with two obvious shoulder peaks at $285 \mathrm{eV}$ and $532 \mathrm{eV}$, which correspond to the characteristic peaks of $\mathrm{C} 1 \mathrm{~s}$ and $\mathrm{O} 1 \mathrm{~s}$, respectively. Figure $\mathbf{4 b}$ indicates the high-resolution spectrum of $\mathrm{C} 1 \mathrm{~s}$ with a major peak at $284.8 \mathrm{eV}$ and a weak peak at $285.8 \mathrm{eV}$, which correspond with the $\mathrm{C}-\mathrm{C}$ and $\mathrm{C}-\mathrm{N}$ bond formation on $\mathrm{sp}^{2}$ carbon, respectively. ${ }^{34}$ Figure $4 \mathbf{c}$ indicates the high-resolution spectrum of $\mathrm{O} 1 \mathrm{~s}$ with a shoulder peak at $532 \mathrm{eV}$, which is ascribed to the
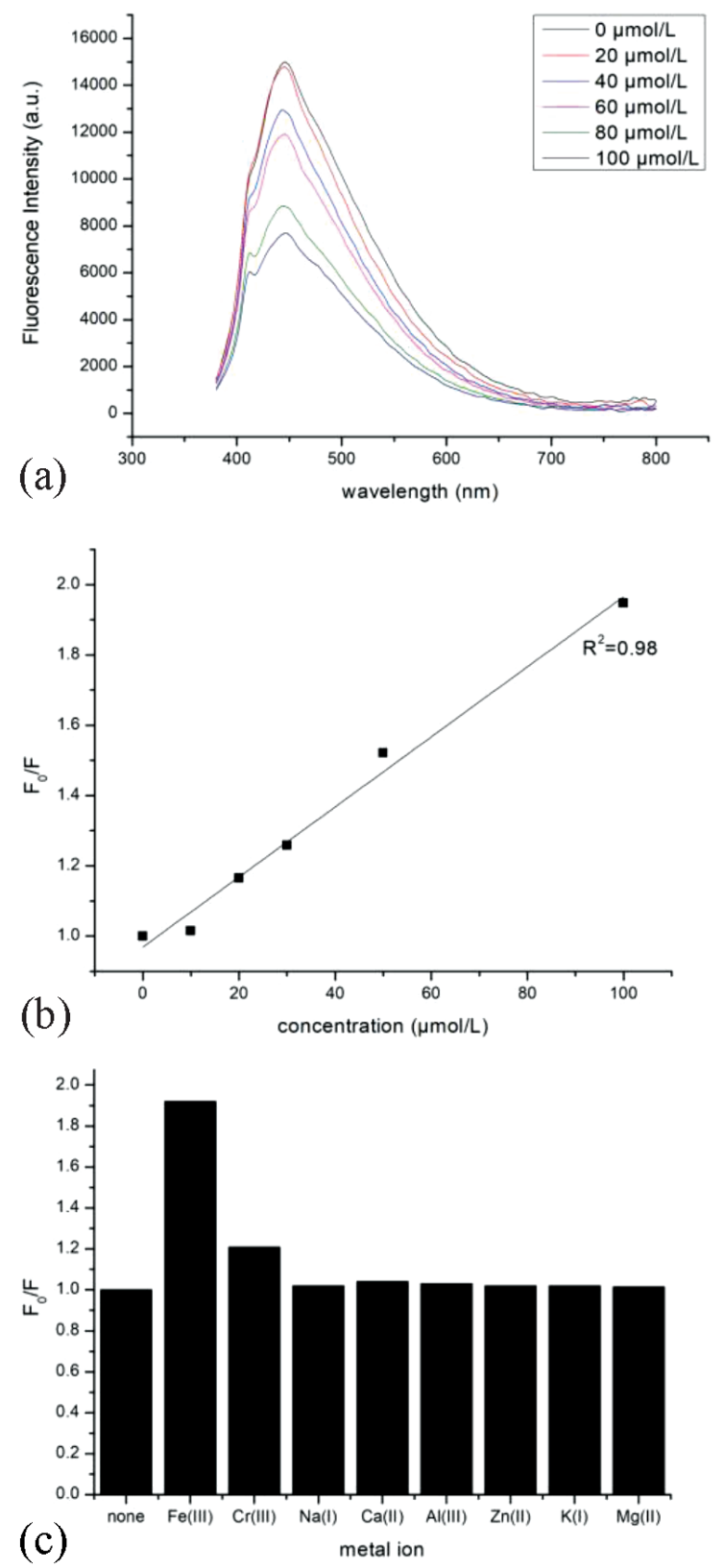

Figure 5: a) Emission spectra of different concentrations of $\mathrm{Fe}(\mathrm{III})$ ions, b) the standard curve of $F_{0} / F$ at a $360 \mathrm{~nm}$ excitation wavelength, c) the quenching efficiency $\left(F_{0} / F\right)$ of other metal ions against $\mathrm{Fe}$ (III) ions
C-OH/C-O-C groups. ${ }^{35}$ The XPS results demonstrate the presence of a water-soluble oxygen-containing function group on the surface of LS-CQDs.

\subsection{Detection of $\mathrm{Fe}(\mathrm{III})$ ions}

Figure 5a displays the emission spectra of LS-CQDs with $\mathrm{Fe}(\mathrm{III})$ concentrations varying from $0 \mu \mathrm{mol} / \mathrm{L}$ to $100 \mu \mathrm{mol} / \mathrm{L}$. An obviously decreased fluorescence intensity at a peak of $449 \mathrm{~nm}$ was observed, indicating the fluorescence-quenching effect of Fe(III) on LS-CQDs.

Figure 5b shows a calibration graph of $F_{0} / F$ versus $\mathrm{Fe}(\mathrm{III})$ concentrations where $\mathrm{F}_{0}$ and $\mathrm{F}$ are the fluorescence intensities of LS-CQDs at $449 \mathrm{~nm}$ without and with varying $\mathrm{Fe}$ (III) concentrations, respectively. An $R^{2}$ value of 0.98 was obtained, suggesting a positive correlation between the $F_{0} / F$ of LS-CQDs and the concentrations of $\mathrm{Fe}(\mathrm{III})$. In addition, the results also show the suitability of LS-CQDs for the determination of Fe(III) ions.

Figure 5c shows the fluorescence quenching efficiency $\left(\mathrm{F}_{0} / \mathrm{F}\right)$ of the other metal ions (i.e., $\mathrm{Al}^{3+}, \mathrm{Ca}^{2+}$, $\mathrm{Cr}^{3+}, \mathrm{K}^{+}, \mathrm{Mg}^{2+}, \mathrm{Na}^{+}$and $\mathrm{Zn}^{2+}$ ) on LS-CQDs at the same concentration $(100 \mu \mathrm{mol} / \mathrm{L})$. Except for $\mathrm{Cr}(\mathrm{III})$, all the metal ions exhibited no obvious effect on the fluorescence intensity of LS-CQDs, confirming the high selectivity of LS-CQDs for the Fe(III) ion detection.

In this study, no remarkable shift occurs at the emission peak around the center at $449 \mathrm{~nm}$, indicating that the fluorescence-quenching mechanism should probably be attributed to electron transfer. ${ }^{36}$ Further, the kinetic mechanisms of the fluorescence-quenching effect were elucidated.

Typically, fluorescence quenching can be classified with regard to the static and/or dynamic quenching effects. The ground-state complex formation model of the static or dynamic quenching effect was determined in accordance with the Stern-Volmer relationship Equation (3):

$$
F_{0} / F=1+K_{\mathrm{SV}} C_{\mathrm{q}}=1+K_{\mathrm{q}} \tau_{0} \mathrm{C}_{\mathrm{q}}
$$

where $K_{\mathrm{SV}}$ stands for the quenching constant; $\tau_{0}$ represents the average lifetime of LS-CQDs (5.5 ns); and $K_{\mathrm{q}}$ refers to the quenching-rate constant. Notably, $K_{\mathrm{q}}$ was determined to be $4.27 \times 10^{11} \mathrm{M}^{-1} \mathrm{~s}^{-1}$, which is markedly greater than the maximum scatter collision quenching constant $\left(\sim 1.0 \times 10^{10} \mathrm{M}^{-1} \mathrm{~s}^{-1}\right)$. These results indicate the static quenching effect of $\mathrm{Fe}(\mathrm{III})$ on LS-CQDs.

\section{CONCLUSIONS}

CQDs were prepared with a hydrothermal synthesis using LS as the carbon source. The synthesized LS-CQDs exhibited a uniform particle-size distribution (the mean $=2.1 \mathrm{~nm}$ ) and were slightly smaller than the previously reported CQDs. The synthesized LS-CQDs demonstrated wavelength-dependent excitation and emitted a green light at $365 \mathrm{~nm}$. In addition, LS-CQDs were 
employed as a fluorescent probe for the Fe(III) ion detection. With the increasing Fe(III) ion concentration, the fluorescence quenching rate of LS-CQDs on Fe(III) ions was increased. However, the synthesized LS-CQDs still possess the disadvantage of a low QY, which should be improved in future studies.

\section{Acknowledgment}

The authors sincerely thank for the funding from Study on Comprehensive Control of Rocky Desertification and Ecological Service Function Improvement in Karst Peaks (No. 2016YFC0502402).

\section{REFERENCES}

${ }^{1}$ A. K. Das, A. Marwal, V Pareek, Y Joshi, Surface Engineering of Magnetite Nanoparticles by Plant Protein: Investigation into Magnetic Properties, Nano Hybrids \& Composites, 11 (2016), 38-44, doi:10.4028/www.scientific.net/NHC.11.38

${ }^{2}$ P. N Dube, A. Shwetha, B. B Hosetti, Impact of copper cyanide on the key metabolic enzymes of freshwater fish Catla catla (Hamilton), Biotechnology in Animal Husbandry, 30 (2014) 3, 499-508, doi:10.2298/BAH1403499D

${ }^{3}$ V. Mitrovic, A. F. Hernandez, M. Meyer, Role of guanylate cyclase modulators in decompensated heart failure, Heart Fail. Rev., 14 (2009) 4, 309-316, doi:10.1007/s10741-009-9149-7

${ }^{4}$ D. S. Kalinowski, D. R. Richardson, Future of toxicology-iron chelators and differing modes of action and toxicity: the changing face of iron chelation therapy, Chem. Res. Toxicol., 20 (2007) 5, 715-724, doi:10.1021/tx700039c

${ }^{5}$ H. Li, K. Tsay, H. Wang, J. Shen, S. Wu, J. Zhang, N. Jia, S. Wessel, Durability of PEM fuel cell cathode in the presence of $\mathrm{Fe} 3+$ and Al3+, J. Power Sources, 195 (2010) 24, 8089-8093, doi:10.1016/ j.jpowsour.2010.07.003

${ }^{6}$ D. Liu, L. Ma, Target transformation factor analysis for simultaneous determination of $\mathrm{Fe} 3+$ and $\mathrm{Al} 3+$ in rare earth samples, Spectroscopy \& Spectral Analysis, 21 (2001) 3, 353-359, doi:10.1016/S13861425(01)00435-8

${ }^{7}$ D. Song, E. Ma, Z. Sun, H. Zhang, A layer-structured Eu-MOF as a highly selective fluorescent probe for $\mathrm{Fe} 3+$ detection through a cation-exchange approach, J. Mater. Chem., 22 (2012) 33 , 16920-16926, doi:10.1039/c2jm32661b

${ }^{8}$ P. Qi, D. Zhang, Y. Wan, Morphology-tunable polydopamine nanoparticles and their application in Fe3+ detection, Talanta, 170 (2017), 173-179, doi:10.1016/j.talanta.2017.03.093

${ }^{9}$ R. Zhu, T. Wang, D. Wang, Zinc-based CPs for effective detection of $\mathrm{Fe} 3+$ and Cr2O72-ions, New J. Chem., 43 (2019) 3, 1494-1504, doi:10.1039/C8NJ05508D

${ }^{10}$ S. Chaudhary, M. D. Milton, Dicationic imidazolium salts as fluorescent probes for selective detection of $\mathrm{Fe} 3+$ ion in pure aqueous media, J. Photochem. Photobiol. A: Chem., 356 (2018), 595-602 doi:10.1016/j.jphotochem.2018.02.003

${ }^{11}$ W. Wang, N. Gong, H. Yin, Two Stable Terbium-Organic Frameworks Based on Predesigned Functionalized Ligands: Selective Sensing of $\mathrm{Fe} 3+$ Ions and $\mathrm{C} 2 \mathrm{H} 2 / \mathrm{CH} 4$ Separation, Inorg. Chem., 58 (2019) 15, 10295-10303, doi:10.1021/acs.inorgchem.9b01465

${ }^{12}$ J. Chen, X. Jiang, C. Zhang, Reversible Reaction-Based Fluorescent Probe for Real-TimeImaging of Glutathione Dynamics in Mitochondria, Acs Sensors, 2 (2017) 9, 1257-1261, doi:10.1021/acssensors. $7 \mathrm{~b} 00425$

${ }^{13}$ G. Jiang, G. Zeng, W. Zhu, A selective and light-up fluorescent probe for -alactosidase activity detection and imaging in living cells based on an AIE tetraphenylethylene derivative, Chem. Commun., 53 (2017) 32, 4505-4508, doi:10.1039/C7CC00249A

${ }^{14}$ V. K. Singh, V. Singh, P. K. Yadav, Bright-blue-emission nitrogen and phosphorus-doped carbon quantum dots as a promising nanoprobe for detection of $\mathrm{Cr}$ (vi) and ascorbic acid in pure aqueous solution and in living cells, New J. Chem., 42 (2018) 15, 12990-12997, doi:10.1039/C8NJ02126K

${ }^{15}$ V. K. Singh, V. Singh, P. K. Yadav, S. Chandra, Nitrogen doped fluorescent carbon quantum dots for on-off-on detection of $\mathrm{Hg} 2+$ and glutathione in aqueous medium: Live cell imaging and IMPLICATION logic gate operation, J. Photochem. Photobiol. A: Chem., 384 (2019), 112042, doi:10.1016/j.jphotochem.2019.112042

${ }^{16}$ Y. Fu, S. Wu, H. Zhou, Carbon Dots and a CdTe Quantum Dot Hybrid-Based luorometric Probe for Spermine Detection, Ind. Eng. Chem. Res., 59 (2020) 4, 1723-1729, doi:10.1021/acs.iecr.9b06289

${ }^{17}$ J. Yue, L. Li, L. Cao, Two-Step Hydrothermal Preparation of Carbon Dots for Calcium Ion Detection, ACS Applied Materials \& Interfaces, 11 (2019) 47, 44566-44572, doi:10.1021/acsami.9b13737

${ }^{18}$ Z. Zhang, D. Zhang, C. Shi, 3,4-Hydroxypyridinone-Modified Carbon Quantum Dot as a Highly Sensitive and Selective Fluorescent Probe for Rapid Detection of Uranyl Ions, Environmental Science: Nano, 6 (2019) 5, 1457-1465, doi:10.1039/C9EN00148D

${ }^{19}$ Y. Duan, H. Zhang, F. Xu, Inhibition effect of procyanidins from lotus seedpod on mouse B16 melanoma in vivo and in vitro, Food Chem., 122 (2010) 1, 84-91, doi:10.1016/j.foodchem.2010.02.020

${ }^{20}$ Q. He, H. Wang, J. Zhang, Lotus seedpod as a low-cost biomass for potential methylene blue adsorption, Water Science \& Technology A Journal of the International Association on Water Pollution Research, 74 (2016) 11, 2560-2567, doi:10.2166/wst.2016.423

${ }^{21}$ D. Zang, R. Zhu, W. Zhang, Corrosion Resistance: Corrosion-Resistant Superhydrophobic Coatings on Mg Alloy Surfaces Inspired by Lotus Seedpod, Adv. Funct. Mater., 27 (2017) 8, 1605446, doi:10.1002/adfm.201770050

${ }^{22}$ D. Magde, R. Wong, P. G. Fluorescence Quantum Yields and Their Relation to Lifetimes of Rhodamine 6G and Fluorescein in Nine Solvents: Improved Absolute Standards for Quantum Yields, Photochem. Photobiol., 75 (2002) 4, 327-334, doi:10.1562/0031-8655 (2002)0750327fqyatr2.0.Co2

${ }^{23}$ J. Hu, X. Bai, Y. Liu, Functionalized carbon quantum dots with dopamine for tyrosinase activity analysis, Anal. Chim. Acta, 995 (2017), 99-105, doi:10.1016/j.aca.2017.09.038

${ }^{24}$ X. Deng, Y. Feng, H. Li, Detection of Ferric Iron Based on Fluorescence Quenching Effect of N-doped Carbon Quantum Dots, Chinese Journal of Analytical Chemistry, 45 (2017) 10, 1497-1503, doi:10.11895/j.issn.0253-3820.170344

${ }^{25}$ Y. Zhao, Y. Zhang, X. Liu, Novel carbon quantum dots from egg yolk oil and their haemostatic effects, Sci. Rep., 7 (2017) 1 , 4452-4458, doi:10.1038/s41598-017-04073-1

${ }^{26}$ S. Ahmadian, M. Salavat, D. Ghanbari, Hydrothermal green synthesis of magnetic Fe3O4-carbon dots by lemon and grape fruit extracts and as a photoluminescence sensor for detecting of E. coli bacteria, Spectrochimica Acta Part A Molecular \& Biomolecular Spectroscopy, 203 (2018) 5, 481-493, doi:10.1016/j.saa.2018.06.021

${ }^{27}$ B. Luo, H. Yang, B. Zhou, Facile Synthesis of Luffa Sponge Activated Carbon Fiber Based Carbon Quantum Dots with Green Fluorescence and Their Application in Cr(VI) Determination, ACS Omega, 5 (2020) 10, 5540-5547, doi:10.1021/acsomega.0c00195

${ }^{28}$ H. Ding, Y. Ji, J. Wei, Facile synthesis of red-emitting carbon dots from pulp-free lemon juice for bioimaging, Journal of Materials Chemistry B, 5 (2017) 26, 5272-5277, doi:10.1039/c7tb01130j

${ }^{29}$ Y. Dong, H. Pang, H. Yang, Carbon-Based Dots Co-doped with Nitrogen and Sulfur for High Quantum Yield and Excitation-Independent Emission, Angew. Chem. Int. Ed., 52 (2013) 30, 7800-7804, doi:10.1002/anie.201301114

${ }^{30}$ R. Singh, S. Kashayap, V. Singh, QPRTase modified N-doped carbon quantum dots: A fluorescent bioprobe for selective detection of 
neurotoxin quinolinic acid in human serum, Biosens. Bioelectron., 101 (2018) 15, 103-109, doi:10.1016/j.bios.2017.10.017

${ }^{31}$ A. Meng, Q. Xu, K. Zhao, A highly selective and sensitive "on-off-on" fluorescent probe for detecting $\mathrm{Hg}$ (II) based on $\mathrm{Au} / \mathrm{N}$-doped carbon quantum dots, Sensors Actuators B: Chem., 255 (2018) 1, 657-665, doi:10.1016/j.snb.2017.08.028

${ }^{32}$ G. Zhang, L. Hu, K. Zhu, Contribution of oligomer/carbon dots hybrid semiconductor nanoribbon to surface-enhanced Raman scattering property, Applied Surface Science, 364 (2016) 28, 660-669, doi:10.1016/j.apsusc.2015.12.214

${ }^{33}$ S. Zhu, Q. Meng, L. Wang, Highly Photoluminescent Carbon Dots for Multicolor Patterning, Sensors, and Bioimaging, Angewandte Chemie International Edition, 52 (2013) 14, 3953-3957, doi:0.1002/anie.201300519
${ }^{34} \mathrm{X}$. Teng, C. Ma, C. Ge, Green synthesis of nitrogen-doped carbon dots from konjac flour with "off-on" fluorescence by Fe3+ and 1-lysine for bioimaging, Journal of Materials Chemistry B, 2 (2014) 29, 4631-4639, doi:10.1039/C4TB00368C

${ }^{35} \mathrm{~W}$. Wang, Y. Lu, H. Huang, Facile synthesis of water-soluble and biocompatible fluorescent nitrogen-doped carbon dots for cell imaging, Analyst, 139 (2014) 7, 1692-1696, doi:10.1039/C3AN02098C

${ }^{36}$ H. Hamishehkar, B. Ghasemzadeh, A. Naseri, Carbon dots preparation as a fluorescent sensing platform for highly efficient detection of $\mathrm{Fe}(\mathrm{III})$ ions in biological systems, Spectrochimica Acta Part A: Molecular and Biomolecular Spectroscopy, 150 (2015), 934-939, doi:10.1016/j.saa.2015.06.061 